\title{
Fabrication of an Amperometric Flow-Injection Microfluidic Biosensor Based on Laccase for In Situ Determination of Phenolic Compounds
}

\author{
Juan C. Gonzalez-Rivera and Johann F. Osma \\ CMUA, Department of Electrical and Electronics Engineering, University of Los Andes, Cra 1 E No. 19 A-40, Bogota, Colombia \\ Correspondence should be addressed to Johann F. Osma; jf.osma43@uniandes.edu.co
}

Received 18 February 2015; Revised 30 April 2015; Accepted 1 May 2015

Academic Editor: Jinsong Ren

Copyright @ 2015 J. C. Gonzalez-Rivera and J. F. Osma. This is an open access article distributed under the Creative Commons Attribution License, which permits unrestricted use, distribution, and reproduction in any medium, provided the original work is properly cited.

\begin{abstract}
We aim to develop an in situ microfluidic biosensor based on laccase from Trametes pubescens with flow-injection and amperometry as the transducer method. The enzyme was directly immobilized by potential step chronoamperometry, and the immobilization was studied using cyclic voltammetry and electrochemical impedance spectroscopy. The electrode response by amperometry was probed using ABTS and syringaldazine. A shift of interfacial electron transfer resistance and the electron transfer rate constant from $18.1 \mathrm{k} \Omega$ to $3.9 \mathrm{M} \Omega$ and $4.6 \times 10^{-2} \mathrm{~cm} \mathrm{~s}^{-1}$ to $2.1 \times 10^{-4} \mathrm{~cm} \mathrm{~s}^{-1}$, respectively, evidenced that laccase was immobilized on the electrode by the proposed method. We established the optimum operating conditions of temperature $\left(55^{\circ} \mathrm{C}\right), \mathrm{pH}(4.5)$, injection flow rate $\left(200 \mu \mathrm{L} \mathrm{min}^{-1}\right)$, and applied potential $(0.4 \mathrm{~V})$. Finally, the microfluidic biosensor showed better lower limit of detection $(0.149 \mu \mathrm{M})$ and sensitivity $\left(0.2341 \mathrm{nA} \mu \mathrm{M}^{-1}\right)$ for ABTS than previous laccase-based biosensors and the in situ operation capacity.
\end{abstract}

\section{Introduction}

Phenols are employed in several industries in the manufacture of plastics and plasticizers, resins, explosives, drugs, detergents, paper, fungicides, preservatives, dyes, and lubricants $[1,2]$. Most phenolic compounds are toxic, noxious, and mutagenic and have carcinogenic activity [2] that accumulate in the environment and are found in food, potable water, sediments, and soil.

Currently, many organizations have established procedures using colorimetry, gas chromatography, liquid chromatography, capillary electrophoresis, and their variations [3]. Even though these methods attain accurate results for a wide range of phenolic compounds, conventional approaches are time-consuming and cost-intensive and require large volumes of organic solvents. Consequently, a market demand exists for a reliable, portable, simple, and cost-effective detection method of phenolic compounds.

Both enzymatic-based biosensors and microfluidic biosensors have attracted increasing among the different configurations of biosensors [4-8]. Microfluidic biosensors combine the advantages of fluidic microsystems, such as low cost, short analysis time, less consumption of sample and reagents, and portability, with the advantages of biosensors such as selectivity, moderate operational potentials, high sensitivity, specificity, and easiness to be miniaturized and integrated $[3,6,9,10]$. Therefore they have potential in environmental safety, food, and clinic analysis.

The immobilization method is a key parameter for the design and fabrication of microfluidic biosensors [11]. The bioreceptor and the sensor elements can be coupled together with several methods, such as physical adsorption, entrapment, cross-linking, and covalent bonding $[12,13]$. However, enzyme degradation and surface inaccessibility arise with the enzyme immobilization inside a microchannel. Thus, we propose the direct electrochemical immobilization of laccase after the sensor sealing since this technique enables an easier immobilization than traditional techniques.

Amperometry is the most common transducer technique in biosensors because it offers detection in real time $[14,15]$. When this technique is coupled with convective mass transport, the resulting technique-hydrodynamic 
amperometry-offers additional assets such as increased current and sensitivity, quicker steady state, and smaller random contribution from natural convection [16]. Besides, the amount of analyte can be regulated directly by adjusting the flow rate of the flow injection system.

We aim to develop an amperometric flow-injection microfluidic biosensor based on laccase from Trametes pubescens. We studied the electrochemical immobilization of laccase by cyclic voltammetry and electrochemical impedance spectroscopy. The microfluidic biosensor electric response was evaluated with ABTS and syringaldazine, both well-known laccase substrates. The characterization of the biosensor included temperature, $\mathrm{pH}$, flow injection, and applied potential effects on the signal response.

\section{Materials and Methods}

2.1. Reagents and Instrumentation. Glass slides of $76.2 \mathrm{~mm}$ in length and $25.4 \mathrm{~mm}$ in width were purchased at a local store. ABTS (2,2-azino-bis(3-ethylbenzothiazoline-6) sulphonic acid), syringaldazine, anhydrous ethanol, potassium ferricyanide, and potassium ferrocyanide were purchased from Sigma-Aldrich (USA). The developer (Microposit MF319) and positive photoresist (Microposit SC 1827) were purchased from Shipley (USA). Gold wire (Au, 99.99\%) and chromium pieces (Cr, 99.95\%) were purchased from Kurt J. Lesker (USA). PRS-100 positive photoresist stripper, dipotassium phosphate, sulfuric acid $97.8 \%$, and hydrochloric acid $37.2 \%$ were purchased from J. T. Baker (USA). Potassium phosphate monobasic was purchased from AppliChem, (Germany); and nitric acid and hydrofluoric acid $40 \%$ were purchased from Panreac (Spain). PDMS was prepared according to product information from a Sylgard 184 silicone elastomer kit (Dow Corning, USA). All other chemicals used were of analytical degree.

Gold and chrome were deposited on microscopic slides using an Edwards Auto 306 thermal evaporation system at vacuum. The electrode pattern was transferred by an optical lithography maskless exposure system (model SF100, Intelligent Micro Patterning, USA). The electrochemical procedures were measured using an Autolab Potensiostat/Galvanostat PGSTAT128N (Metrohm, USA) computercontrolled. Data were acquired and analyzed by the software Nova version 1.9. All assays were performed in a Faraday cage at room temperature.

2.2. Laccase Production. T. pubescens (CBS 696.94) was cultured on malt extract agar (MEA) plates during 10 days at $30^{\circ} \mathrm{C}$. Cultures were carried out in $1000 \mathrm{~mL}$ shake flasks with $50 \mathrm{~mL}$ of basal medium and $15 \mathrm{~g}$ sterilized dry coffee husk [17]. Culture medium was inoculated with three $13 \mathrm{~mm}$ plugs from active fungus cultured in MEA. In brief, laccase was produced in 11 shake flask with $50 \mathrm{~mL}$ of basal medium and $15 \mathrm{~g}$ sterilized coffee husk. Cultured medium was inoculated and incubated during 21 days at $30^{\circ} \mathrm{C}$ under static condition. The enzymatic crude extract was removed by filtration through $10 \mu \mathrm{m}$ filter paper (Boeco, Germany) and then centrifuged at $4^{\circ} \mathrm{C}$ and $4500 \mathrm{rpm}$ for $15 \mathrm{~min}$. Finally, the crude extract was filtered through $0.22 \mu \mathrm{m}$ Millex filter unit (Millipore, USA).
2.3. Free Laccase Activity Assay and Protein Measurement. The activity of free laccase was determined spectrophotometrically by measuring the absorbance change for $10 \mathrm{~min}$ using $\operatorname{ABTS}\left(\varepsilon_{420}=36 \mathrm{mM}^{-1} \mathrm{~cm}^{-1}\right)$ as a substrate at room temperature. To perform the assay, $950 \mu \mathrm{L}$ of $0.5 \mathrm{mM}$ of ABTS in acetate buffer $(0.1 \mathrm{M}, \mathrm{pH} 5.0)$ was mixed with $50 \mu \mathrm{L}$ of laccase crude extract. The enzyme activity was expressed as units per liter $\left(\mathrm{Ul}^{-1}\right)$, where $\mathrm{U}$ was defined as the amount of enzyme required to oxidized $1 \mu \mathrm{mol}$ ABTS per minute. Protein concentration was determined by Lowry assay [18].

2.4. Microfluidic Biosensor Fabrication. The device is composed of an upper glass slide with a fluidic microsystem and a lower glass slide with an integrated three-electrode arrangement made of gold (Figure 1(a)). Both pieces were fabricated through separate steps and assembled forward electrode modification with laccase. An in-channel configuration for the microfluidic biosensor was selected because it is the most preferred choice of amperometric microchip sensors [19]. The final device has a length of $35 \mathrm{~mm}$ and a width of $25 \mathrm{~mm}$.

2.4.1. Fabrication of the Gold Electrodes. The arrangement of gold electrodes was fabricated using first a chrome and latter a gold thin film deposition on glass slides by physical vapor deposition using a thermal evaporator Edwards E306 (Moorfield, UK) at $2.8 \mathrm{~A}$ with the metals on a tungsten slide at a vacuum pressure of $4 \times 10^{-5} \mathrm{mbar}$ and an evaporation rate of $0.3 \mathrm{~nm} / \mathrm{min}$ [20]. The chrome/gold deposition presented an overall thickness of $50 \mathrm{~nm}$. The working electrode (WE) and reference electrode (RE) were fabricated with a diameter of 200 and $300 \mu \mathrm{m}$, respectively. The counter electrode (CE) was fabricated with a transverse diameter of $1 \mathrm{~mm}$ and a conjugate diameter of $500 \mu \mathrm{m}$.

Before the deposition of the gold layer, a chrome intermediate layer of $5 \mathrm{~nm}$ was evaporated to enhance the adhesion between the glass and gold. The electrode pattern was transferred over the metallic film by using mask-free optical lithography equipment with a resolution of $5 \mu \mathrm{m}$. Positive photoresist was spin-coated onto the gold film at $3600 \mathrm{rpm}$ for $60 \mathrm{~s}$. Then, the photoresist was baked during $60 \mathrm{~s}$ at $115^{\circ} \mathrm{C}$ and patterned for $16 \mathrm{~s}$. Finally, the soluble photoresist was removed submerging the substrate in the developer for $120 \mathrm{~s}$ with constant agitation.

The exposed gold areas were etched using aqua regia $\left(\mathrm{HCl}+\mathrm{HNO}_{3} 3: 1 \mathrm{v} / \mathrm{v}\right)$ for $5 \mathrm{~s}$, and then the chrome was removed submerging the substrate for $30 \mathrm{~s}$ in $\mathrm{HF} 40 \% \mathrm{v} / \mathrm{v}$. The residual baked photoresist was removed using stripper for $60 \mathrm{~s}$ leaving the three electrodes created on top of the glass slide (Figure 1(b) bottom).

2.4.2. Fabrication of the Fluidic Microsystem. Copper foil tape was stuck on a glass slide, and the fluidic microsystem mask was transferred to the substrate by mask-free technology optical lithography, as was described for the electrode fabrication. Next, the copper pattern-obtained after the development-was exposed to $\mathrm{FeCl}_{3} 52 \%(\mathrm{w} / \mathrm{v}$ ) with the aim to remove the unprotected copper and fabricate a physical mask for glass etching. Then, this slide with the pasted mask 


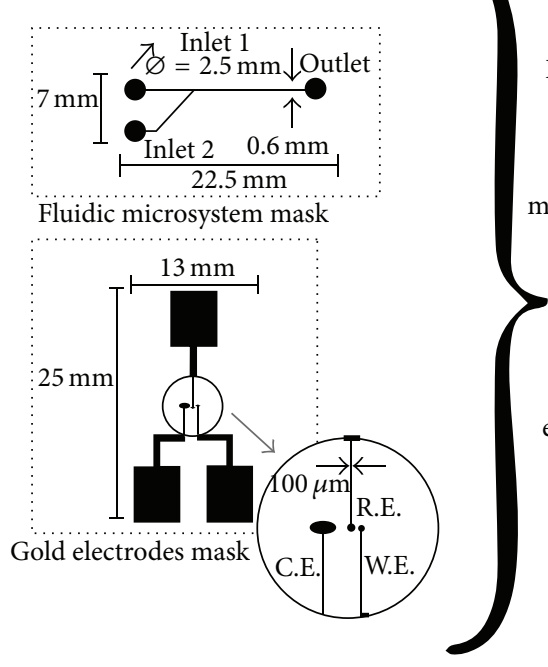

(a)

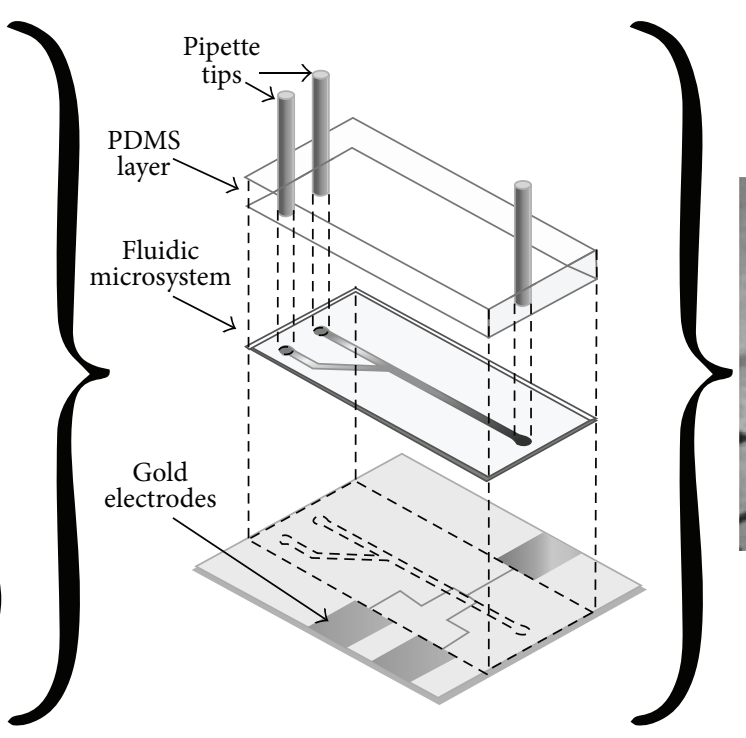

(b)

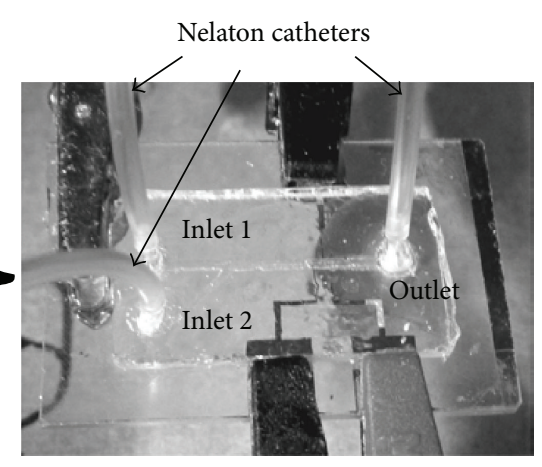

(c)

FIGURE 1: Masks and dimensions of the microfluidic biosensor (a); dismantled schematic diagram (b); and experimental set-up (c).

was submerged into an HF $40 \%$ solution for 4 min for glass etching. Therefore, a microchannel of $600 \mu \mathrm{m}$ of width and $250 \mu \mathrm{m}$ of depth was obtained in the glass slide. Finally, the copper mask was removed with $\mathrm{FeCl}_{3} 52 \%$ (w/v) leaving the glass fluidic microsystem clean of any sacrificial layers (Figure 1(b) middle).

The fluidic microsystem inlets and outlet were perforated in the glass fluidic microsystems using a commercial mototool (Figure 1(b) top). The holes were drilled-immersed in water-at 17,000 rpm using a diamond coated tip.

2.4.3. Microfluidic Sensor Assembly. The fluidic microsystem and electrodes slides were assembled using UV curable epoxy. Previous to coating the fluidic microsystem slide with a glue layer, the microchannel was protected by filling it with positive photoresist to prevent channel clogging. After sealing both slides (Figure 1(b) bottom and middle) with UV curable epoxy, stripper was used to remove the positive photoresist from the microchannels.

Micropipette tips $(0.2-10 \mu \mathrm{L})$ were cut and used as connections between reservoirs and tubes. These tips were coupled in the inlets and outlet reservoirs of the fluidic microsystem using a layer of PDMS with a thickness of $2 \mathrm{~mm}$ (Figure 1(c)). The connectors were joined to Nelaton catheters that were coupled to the syringes.

2.4.4. Laccase Immobilization. Laccase with an enzymatic activity of $2.13 \mathrm{U} \mathrm{mg}^{-1}$ of protein was selectively deposited on the working electrode inside the sealed fluidic microsystem by potential step chronoamperometry. To attain this process, a stream of crude extract of laccase (with a protein concentration of $0.178 \mathrm{mg} \mathrm{mL}^{-1}$ ) in $0.1 \mathrm{M}$ phosphate buffer $(\mathrm{pH}$ 7.0) purged with high purity nitrogen was driven into the fluidic microsystem. Initial potential was set at the opencircuit potential. After $10 \mathrm{~s}$ of initial holding, laccase was immobilized by applying $1.2 \mathrm{~V}$ between the counter electrode and the working electrode for $3 \mathrm{~min}$.

Prior to use, the electrodes were electrochemically cleaned using a $0.1 \mathrm{M} \mathrm{H}_{2} \mathrm{SO}_{4}$ solution by successive cycling between -0.2 and $1.5 \mathrm{~V}$ at $500 \mathrm{mV} \mathrm{s}^{-1}$ until reproducible voltammograms were achieved (Figure 2(b)).

After laccase immobilization, $25 \mu \mathrm{M}$ ABTS in acetate buffer $0.1 \mathrm{M}$ ( $\mathrm{pH}$ 5.0.) was introduced in the sealed fluidic microsystems to test possible undesirable adsorption of laccase on the glass surface. No undesired laccase adsorption was detected through high magnification optical $(>\times 1000)$ after several hours of ABTS exposure.

2.5. Electrochemical Study of Laccase Immobilization. Cyclic voltammetry $(\mathrm{CV})$ and electrochemical impedance spectroscopy (EIS) were performed in $0.1 \mathrm{M}$ phosphate buffer (pH 7.0) containing $1 \mathrm{mM} \mathrm{Fe}(\mathrm{CN})_{6}{ }^{3-/ 4-}$, due to the reasonably fast electron transfer. Voltammograms were scanned at $100 \mathrm{mV} \mathrm{s}^{-1}$ between -0.2 and $0.6 \mathrm{~V}$. The frequency scan range for the EIS was from $0.1 \mathrm{~Hz}$ to $100 \mathrm{kHz}$ and a sinusoidal potential modulation of $\pm 5 \mathrm{mV}$ was superimposed on the $\mathrm{DC}$ potential of $0.2 \mathrm{~V}$. Before each experiment, fresh solution was purged for $10 \mathrm{~min}$ using high purity nitrogen. We selected the Randles circuit to fit the experimental data obtained by EIS; this circuit is comprised by a solution resistance $\left(R_{s}\right)$, a charge transfer resistance $\left(R_{\mathrm{ct}}\right)$, a Warburg impedance $(W)$, and a double layer capacitance $\left(C_{\mathrm{dl}}\right)$. The diameter of the semicircle corresponds to the interfacial electron transfer resistance $\left(R_{\mathrm{ct}}\right)$.

2.6. Characterization of the Microfluidic Biosensor Experimental Conditions. Temperature and $\mathrm{pH}$ effect on the immobilized laccase activity were studied by CV using ABTS as a substrate. Acetate buffer $0.1 \mathrm{M}(\mathrm{pH} 5.0)$ with ABTS $25 \mu \mathrm{M}$ was injected into the fluidic microsystem, and five voltammograms were scanned at $100 \mathrm{mV} \mathrm{s}^{-1}$ between -0.2 


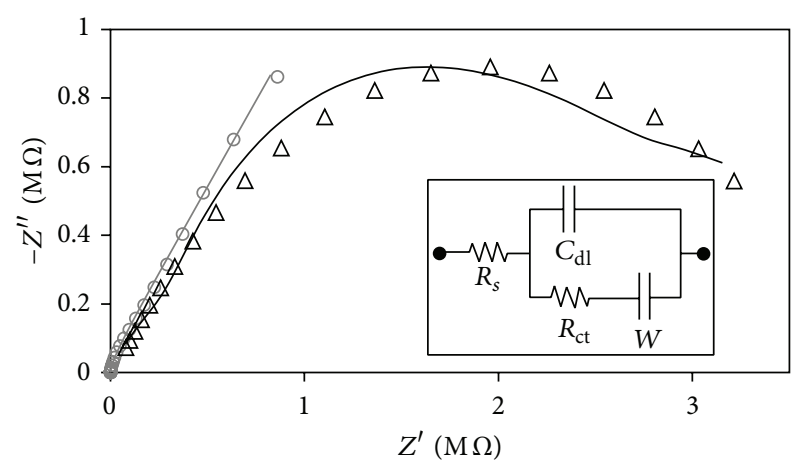

(a)

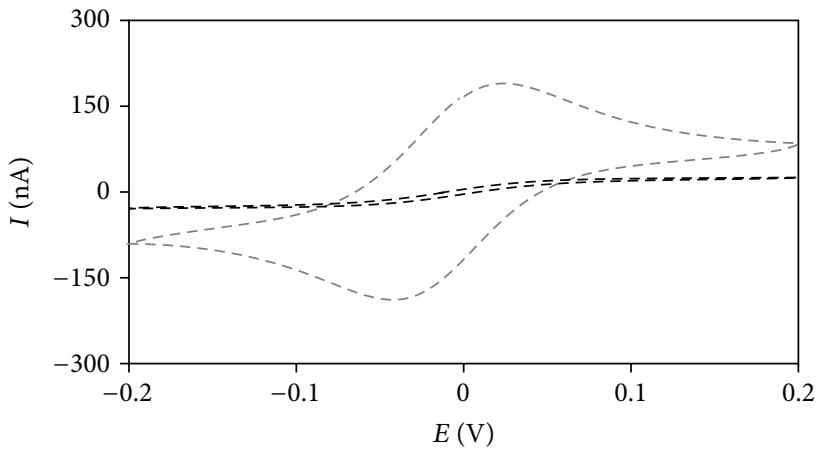

(b)

FIGURE 2: Nyquist plots (a) and cyclic voltammograms (b) at bare electrode (gray) and laccase modified Au electrode sealed in the fluidic microsystem (black). Continuous lines represent results from data fitting. Inset is the equivalent circuit. Solution: $1 \mathrm{mM} \mathrm{K}_{4}\left[\mathrm{Fe}(\mathrm{CN})_{6}\right]+$ $\mathrm{K}_{3}\left[\mathrm{Fe}(\mathrm{CN})_{6}\right]+0.1 \mathrm{M}$ phosphate buffer (pH. 7.0). For EIS, a sinusoidal potential modulation of $\pm 5 \mathrm{mV}$ was superimposed on the DC potential of $0.2 \mathrm{~V}$ versus $\mathrm{Ag} / \mathrm{AgCl} / \mathrm{KCl}_{3 M}$. Applied frequency was from $10^{6}$ to $0.1 \mathrm{~Hz}$. For CV the scan rate was $100 \mathrm{mV} \mathrm{s}^{-1}$.

and $1 \mathrm{~V}$. For each experiment the anodic peak height of the second voltammogram was plotted against the independent variable. Temperature effect was evaluated in the range from $20^{\circ} \mathrm{C}$ to $75^{\circ} \mathrm{C}$ at $\mathrm{pH}$ 5.0. Similarly, the buffer $\mathrm{pH}$ was varied from 4.0 to 7.5 at room temperature.

Injection flow rate effect on the immobilized laccase activity was evaluated by amperometry using acetate buffer $0.1 \mathrm{M}(\mathrm{pH} 5.0)$ as the running solution. The amperometry experiments with flow injection were conducted using the following procedure. The fluidic microsystem was treated with the running solution for $5 \mathrm{~min}$. This solution was delivered into the fluidic microsystem using a syringe pump at a fixed flow rate. Then, ABTS $25 \mu \mathrm{M}$ in acetate buffer $0.1 \mathrm{M}(\mathrm{pH}$ 5.0.) was injected into the fluidic microsystem - through the inlet 2-using another syringe pump at the same rate of the running solution. The injection flow rate effect was evaluated at $100,120,140,160,180,240$, and $320 \mu \mathrm{L} \mathrm{min}^{-1}$ applying $0.4 \mathrm{~V}$. The current signal obtained was plotted against the independent variable. Each experiment was performed by triplicate. Data was plotted as relative current, which was defined regarding the maximum value of each experiment.

\subsection{ABTS and Syringaldazine Detection Determination.} ABTS and syringaldazine detection experiments were measured by amperometry with flow injection. The injection flow rate, buffer $\mathrm{pH}$, and potential applied were chosen based on the results of the characterization of the experimental conditions. ABTS probes were performed with $0.1 \mathrm{M}$ acetate buffer as the running buffer, and syringaldazine probes with $0.1 \mathrm{M}$ acetate buffer-ethanol mixture prepared in a proportion $1: 1(\mathrm{v} / \mathrm{v})$. Probes were made injecting continuously running buffer and the analyte was injected periodically each $120 \mathrm{~s}$ for $20 \mathrm{~s}$ increasing its concentration periodically. Experiments were conducted in triplicate and at room temperature unless specified.

We calculated the Michaelis-Menten parameters from the Lineweaver-Burk equation:

$$
\frac{1}{I}=\frac{K_{M}^{\mathrm{app}}}{I_{\max }[S]}+\frac{1}{I_{\max }},
$$

where $I$ is the current response, $K_{M}^{\text {app }}$ is the apparent Michaelis-Menten constant and $I_{\max }$ is the maximum current measured under saturated substrate condition.

2.8. Stability of the Microfluidic Biosensor. The stability test followed the previous procedure for ABTS detection by amperometry with flow injection. Measurements were made each $24 \mathrm{~h}$ for 10 days (in triplicate at room temperature) using $0.1 \mathrm{M}$ acetate buffer as the running buffer and $50 \mu \mathrm{M}$ ABTS in acetate buffer $0.1 \mathrm{M}(\mathrm{pH} \mathrm{5.0)}$ as the analyte solution for detection under the same conditions as for ABTS detection determination. The microfluidic biosensor was stored at $4^{\circ} \mathrm{C}$ after the measurements.

\section{Results and Discussion}

3.1. Laccase Immobilization. We determined the immobilization of laccase studying the electrochemical behavior of the working electrode. Previous the immobilization, the Nyquist profile shows a small semicircular profile at high frequencies, followed by a linear profile at low frequencies (Figure 2(a)). After the immobilization, the electrode only shows a semicircular profile within the frequency range evaluated. The estimated values of the interfacial electron transfer resistance $\left(R_{\mathrm{ct}}\right)$ from the Randles model were $18.1 \mathrm{k} \Omega$ and $3.9 \mathrm{M} \Omega$ for the bare electrode and laccase-modified electrode, respectively.

We calculated the electron transfer rate constant $\left(k^{0}\right.$, an indicator of the kinetic facility of the redox system) by EIS [21]. The following equations were applied for the 1-electron, first order reaction of the $\mathrm{Fe}(\mathrm{CN})_{6}{ }^{3-/ 4-}$ couple, assuming that $C_{\mathrm{ox}}=C_{\mathrm{red}}=C$, in order to determine $k^{0}[22]$ :

$$
\begin{aligned}
R_{\mathrm{ct}} & =\frac{R T}{F i_{0}} \\
i_{0} & =F A k^{0} C,
\end{aligned}
$$

where $R$ is the gas constant, $T$ is the temperature, $F$ is the Faraday constant, and $A$ is the area of gold electrode. The $k^{0}$ 


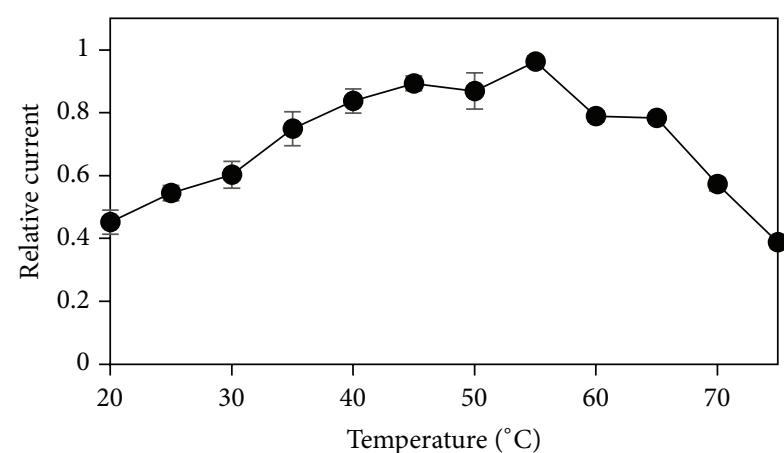

(a)

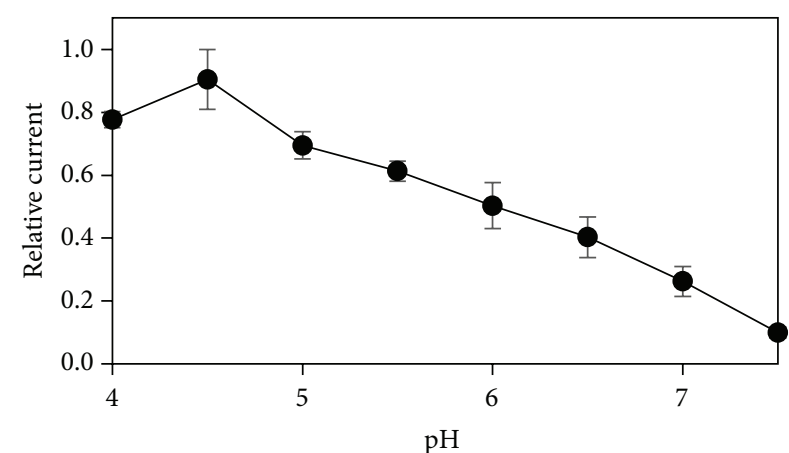

(b)

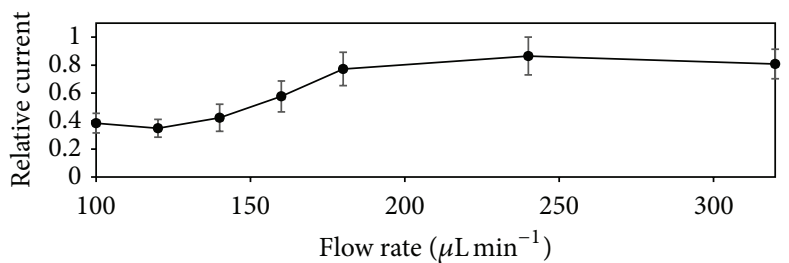

(c)

FIGURE 3: Effect of temperature (a), $\mathrm{pH}(\mathrm{b})$, and injection flow rate (c) on the current response of the microfluidic biosensor. Error bars describe the standard deviation of the three replicates. Solution: acetate buffer $0.1 \mathrm{M}$ (pH 5.0.) as the running solution and ABTS $25 \mu \mathrm{M}$ in acetate buffer $0.1 \mathrm{M}$ (pH 5.0.) as the analyte.

measured were $4.6 \times 10^{-2} \mathrm{~cm} \mathrm{~s}^{-1}$ and $2.1 \times 10^{-4} \mathrm{~cm} \mathrm{~s}^{-1}$ for the bare and laccase-modified electrode, respectively.

Figure 2(b) shows the CV profiles obtained from the reaction of $\mathrm{Fe}(\mathrm{CN})_{6}{ }^{3-/ 4-}$ at the electrode interface before and after the immobilization of laccase. $\mathrm{Fe}(\mathrm{CN})_{6}{ }^{3-/ 4-}$ was used due to the reasonably fast electron transfer; however, by means of the modification of the charge transfer resistance and the electron transfer rate constant, the electrochemical immobilization of laccase on the electrode surface was evidenced. Previous the immobilization, the anodic and cathodic peak heights were 181.1 and $170.4 \mathrm{nA}$, respectively, and the peak separation was $54 \mathrm{mV}$. After the immobilization, the anodic and cathodic peak heights were 13.0 and $12.7 \mathrm{nA}$ respectively, while the peak separation was $117 \mathrm{mV}$.

We induced the electrolysis of water applying a potential between the working and counter electrode in a buffer $(\mathrm{pH}$ 7.0) containing laccase. A decrease of the local $\mathrm{pH}$ in the vicinity of the working electrode produced the neutralization of laccase net charge ( $\mathrm{pI} 2.6$ for laccase from Trametes pubescens [23]). This process caused the precipitation of the enzyme on the surface of the working electrode [24, 25].

We found that laccase was immobilized on the electrode sealed inside the fluidic microsystem by this electrochemical technique without exposing laccase to denaturing conditions. The change of the Nyquist profiles showed that the $\mathrm{Fe}(\mathrm{CN})_{6}{ }^{3-/ 4-}$ reaction was initially limited by the mass transfer of the active specie from the bulk solution to the electrode interface, but the reaction shifted to kinetic-limited after the immobilization [16]. This change is evidenced by the decrease of two orders of magnitude of $k^{0}$ and the increase of $R_{\mathrm{ct}}$. This behavior means that the $\mathrm{Fe}(\mathrm{CN})_{6}{ }^{3-/ 4-}$ reaction was harder to accomplish due to the presence of a layer of laccase on the surface of the working electrode, which decreased the active area of the electrode. After the immobilization, we also observed a decrease of an order of magnitude in the current response and an increase of $54 \%$ in the potential separation of the peaks by CV. These observations proved that the reaction-initially reversible-became irreversible with the functionalization of the electrode. These observations proved the hypothesis that laccase was immobilized by the electrochemical technique performed in this work.

3.2. Characterization of Experimental Conditions of the Microfluidic Biosensor. Figure 3 shows the resulting relative current from the ABTS oxidation by the working electrode modified with laccase when we evaluated the effect of temperature, $\mathrm{pH}$, injection flow rate, and potential applied on the current response. The temperature profile achieved a maximum around $55^{\circ} \mathrm{C}$, while the $\mathrm{pH}$ profile showed a maximum around 4.5 (Figures $3(\mathrm{a})$ and $3(\mathrm{~b})$ ). We found previously using free laccase from Trametes pubescens and ABTS as a substrate that the temperature profile behaved like a bell-shape with a maximum around $55^{\circ} \mathrm{C}$, and the $\mathrm{pH}$ profile decreased as the $\mathrm{pH}$ increased, with a maximum in a range from 2 to 3 [26]. These profiles behaved similarly compared to the profiles from the present work, which may indicate that the electrochemical immobilization proceeded without modify the structure of the enzyme.

The maximum current was achieved at a temperature higher than previous laccase-based biosensors using nanomaterial composites and polymers [27-29] and similar to laccase immobilized on magnetic chitosan microparticles $\left(55^{\circ} \mathrm{C}\right)[30]$. Also, the behavior of $\mathrm{pH}$ profile is consistent with previous biosensors characterizations [31, 32]. 


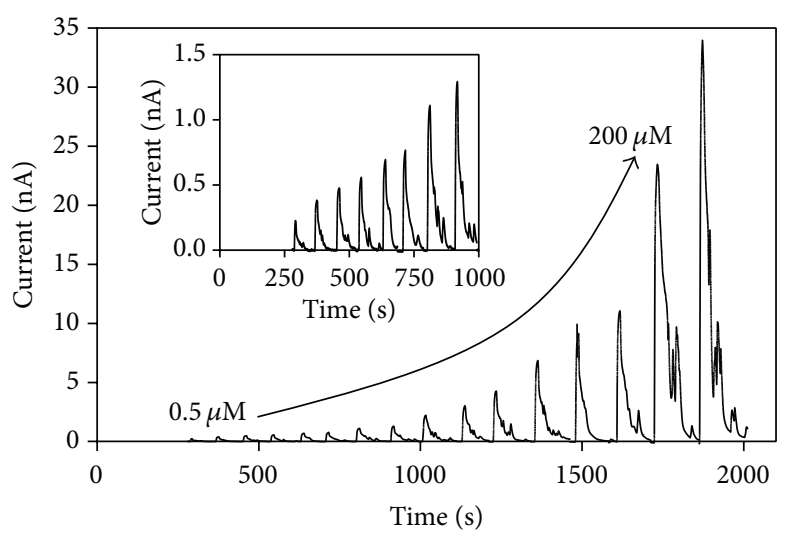

(a)

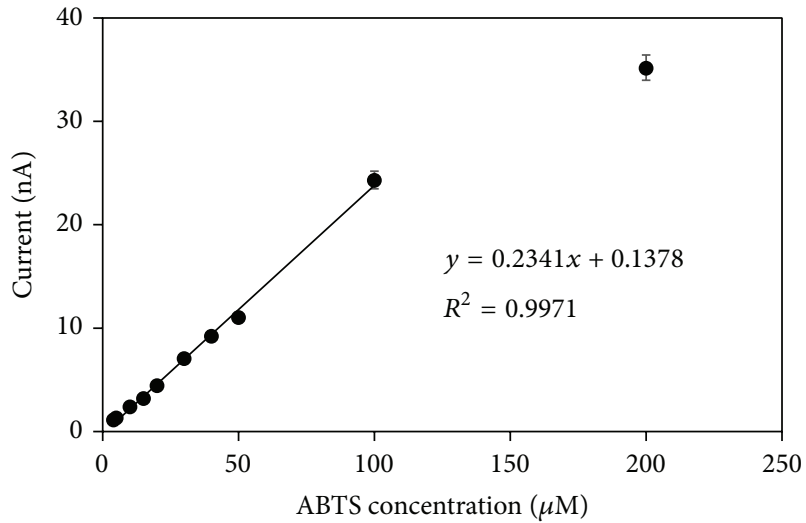

(b)

Figure 4: Current-time response curve with background signal subtracted (a) and calibration curve (b) of the microfluidic biosensor. Increasing concentrations of ABTS (from $0.5 \mu \mathrm{m}$ to $200 \mu \mathrm{M}$ ) in $0.1 \mathrm{M}$ acetate buffer ( $\mathrm{pH} 4.5$ ) were injected at $200 \mu \mathrm{L} \mathrm{min}^{-1}$. Potential applied of $0.4 \mathrm{~V}$ at room temperature. Error bars describe the standard deviation of the three replicates.

Figure 3(c) shows that the current increases with the flow rate from 100 to $180 \mu \mathrm{L} \mathrm{min}^{-1}$, and after the turning point around $180 \mu \mathrm{L} \mathrm{min}^{-1}$ the current became constant. Before the turning point, heterogeneous mass transfer kinetic is higher than the rates of mass transfer; therefore the reaction is kinetic controlled. After the turning point, the convective contribution to mass transfer became larger to increase the mass transfer rates turning to a mass-transfer controlled reaction. Based on these results, we selected a temperature of $55^{\circ} \mathrm{C}$, a buffer $\mathrm{pH}$ of 4.5 , an injection flow rate of $200 \mu \mathrm{L} \mathrm{min}^{-1}$, and a potential applied of $0.4 \mathrm{~V}$ as the optimal conditions for phenolic determination.

3.3. Detection of ABTS. Figure 4 shows the current response achieved at different concentrations of ABTS. We achieved a linear relationship within 0.5 and $100 \mu \mathrm{M}$ with a relative standard deviation (RSD) lower than $5 \%$. The ABTS sensitivity and the detection limit (signal-to-noise ratio $(\mathrm{S} / \mathrm{N})=$ 3) calculated were $0.2341 \mathrm{nA} \mu \mathrm{M}^{-1}\left(741 \mathrm{nA} \mu \mathrm{M}^{-1} \mathrm{~cm}^{-2}\right)$ and $0.149 \mu \mathrm{M}$, respectively. The apparent Michaelis-Menten constant $\left(K_{M}^{\mathrm{app}}\right)$ and the maximum current $\left(I_{\max }\right)$ were $386.5 \mu \mathrm{M}$ and $105 \mathrm{nA}$, respectively. The sampling rate of the microfluidic biosensor calculated was 24 to 60 samples per min.

The substrate sensitivity was improved compared with the laccase electrode covalently immobilized on platinum and

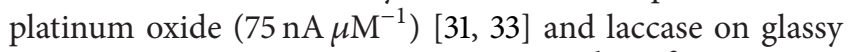
carbon electrodes $\left(358.3 \pm 18.8 \mathrm{nA} \mu \mathrm{M}^{-1} \mathrm{~cm}^{-2}\right)$ [34]. The detection limit was also lower than those reported in previous results for amperometric laccase biosensors on platinum $(0.2 \mu \mathrm{M})$ and platinum oxide $(0.5 \mu \mathrm{M})[31,33]$, as well as the laccase biosensor based on a matrix of carbon nanotubeschitosan composite $(0.23 \mu \mathrm{M})$ [32].

Figure 5 shows the stability of the microfluidic biosensor. This test showed a linear decrease with a coefficient of determination $\left(R^{2}\right)$ of 0.9924 , and a half-life time of 10 days. The relative standard deviation was lower than $10 \%$.

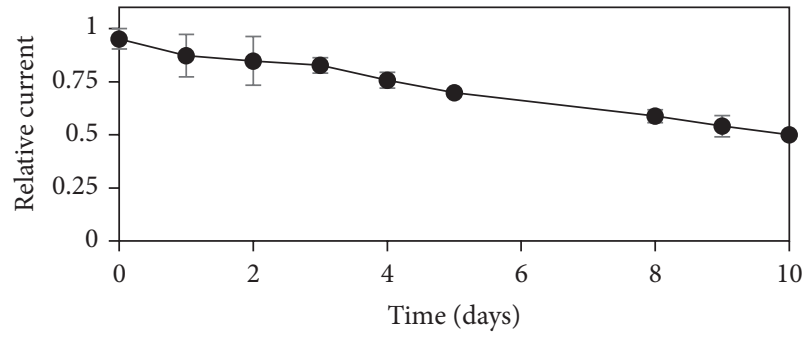

FIGURE 5: Stability of the microfluidic biosensor. Measurements made each $24 \mathrm{~h}$ for 10 days using $0.1 \mathrm{M}$ acetate buffer as the running buffer and $50 \mu \mathrm{M}$ ABTS in acetate buffer $0.1 \mathrm{M}$ ( $\mathrm{pH}$ 5.0.) as the analyte solution for detection. Error bars describe the standard deviation of the three replicates.

3.4. Detection of Syringaldazine. Figure 6 shows the current response achieved at different concentrations of syringaldazine; we achieved a linear relationship within 10 and $200 \mu \mathrm{M}$ with a relative standard deviation (RSD) lower than $10 \%$. The syringaldazine sensitivity and the lowest detectable

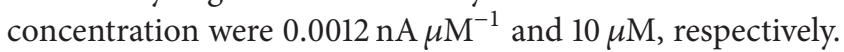
The apparent Michaelis-Menten constant $\left(K_{M}^{\text {app }}\right)$ and the maximum current $\left(I_{\max }\right)$ were $540 \mu \mathrm{M}$ and $0.9 \mathrm{nA}$, respectively. Also, the microfluidic biosensor is capable of measure 60 syringaldazine samples per min.

We found that the sensitivity and the repeatability for syringaldazine decreased compared with ABTS values. This biosensor has a ABTS limit of detection comparable to the biosensor of laccase covalently immobilized on a composite of silver nanoparticles, carboxylated multiwalled carbon nanotubes and polyaniline on a gold surface [35], a laccase biosensor based on platinum nanoparticles dispersed in 1butyl-3-methylimidazolium hexafluorophosphate [36], and a laccase based biosensor immobilized on magnetic core-shell nanoparticles, but lower for the detection of syringaldazine [37]. Apparently ethanol, which has a lower polarity than 


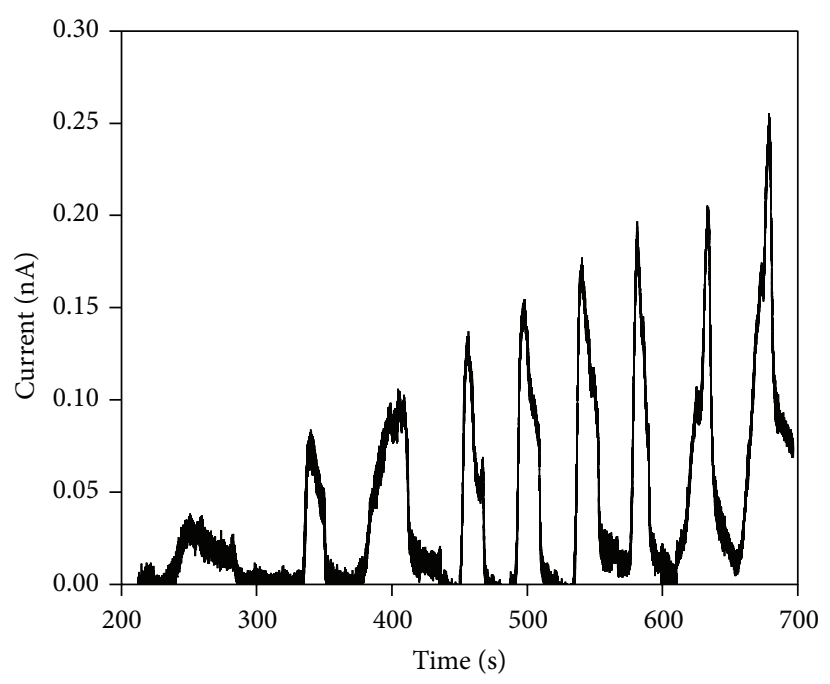

(a)

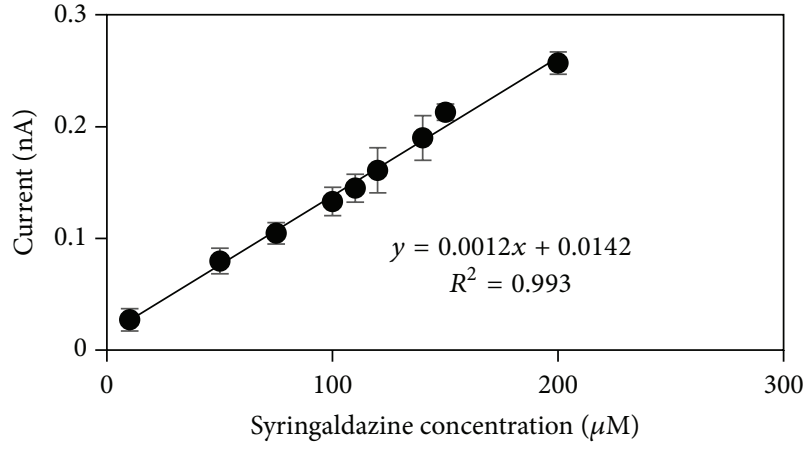

(b)

FiguRE 6: Current-time response curve with background signal subtracted (a) and calibration curve (b) of the microfluidic biosensor. Increasing concentrations of syringaldazine (from $10 \mu \mathrm{m}$ to $200 \mu \mathrm{M}$ ) in $0.1 \mathrm{M}$ acetate buffer (pH 4.5) : ethanol 1:1 (v/v) solution were injected at $200 \mu \mathrm{L} \mathrm{min}^{-1}$. Potential applied of $0.4 \mathrm{~V}$ at room temperature. Error bars describe the standard deviation of the three replicates.

water (relative permittivity: $\varepsilon_{r \mathrm{H} 2 \mathrm{O}}=78.5 ; \varepsilon_{r \mathrm{C} 2 \mathrm{H} 6 \mathrm{O}}=24.5$ at $25^{\circ} \mathrm{C}$ ), affected the performance of the biosensor; as polarity promotes the dissociation of dissolved electrolytes and hydration of the ions, the ion mobility was much harder [38]. However, this should not be a problem in real sample since ethanol has a high volatility, and phenolic compounds can be found in aqueous solutions.

\section{Conclusions}

The complete process of fabrication, assembling, and enzymatic immobilization of a microfluidics biosensor for the detection of phenol is described. This microfluidics system can be functionalized after the microfabrication process takes place and the microdevice is sealed and operates in both stationary and continuous flow conditions. The material of the substrate and the confinement of the electrodes allow this microdevice to be operated in situ without any risk of deterioration or contamination of the sample. In addition, a small volume is needed to detect phenol in aqueous solutions thanks to the microchannel structure. The microfluidic biosensor showed better analytic characteristics than previous biosensors, such as the lower limit of detection and sensitivity. Moreover, the optimum operational conditions of temperature, $\mathrm{pH}$, injection flow rate, and potential were established and can be directly applied to in situ operation as well as its fabrication procedure introduced for industrial applications.

\section{Abbreviation}

ABTS: 2,2-Azino-bis(3-ethylbenzothiazoline-6) sulphonic acid

ASTM: International Association of Testing Materials
CE: Counter electrode

CV: Cyclic voltammetry

EIS: Electrochemical impedance spectroscopy

EPA: Environmental Protection Agency

ISO: International Organization for Standardization

RE: Reference electrode

RSD: Relative standard deviation

WE: Working electrode.

\section{Conflict of Interests}

The authors declare that there is no conflict of interests regarding the publication of this paper.

\section{Acknowledgments}

This project was possible thanks to the collaboration of the Department of Electrical and Electronics Engineering, the Department of Mechanical Engineering, the Department of Chemical Engineering, and the personnel of the Clean Room of Universidad de los Andes.

\section{References}

[1] V. Glezer, "Environmental effects of substituted phenols," in The Chemistry of Phenols, Z. Rappoport, Ed., pp. 1347-1368, John Wiley \& Sons, West Sussex, UK, 2003.

[2] J. Michałowicz and W. Duda, "Phenols: sources and toxicity," Polish Journal of Environmental Studies, vol. 16, no. 3, pp. 347362, 2007.

[3] F. Karim and A. N. M. Fakhruddin, "Recent advances in the development of biosensor for phenol: a review," Reviews in Environmental Science and Biotechnology, vol. 11, no. 3, pp. 261274, 2012. 
[4] K. Morimoto, S. Upadhyay, T. Higashiyama et al., "Electrochemical microsystem with porous matrix packed-beds for enzyme analysis," Sensors and Actuators B: Chemical, vol. 124, no. 2, pp. 477-485, 2007.

[5] P.-C. Nien, M.-C. Huang, F.-Y. Chang, and K.-C. Ho, "Integrating an enzyme-entrapped conducting polymer electrode and a prereactor in a microfluidic system for sensing glucose," Electroanalysis, vol. 20, no. 6, pp. 635-642, 2008.

[6] Y. Wang, Q. He, Y. Dong, and H. Chen, "In-channel modification of biosensor electrodes integrated on a polycarbonate microfluidic chip for micro flow-injection amperometric determination of glucose," Sensors and Actuators, B: Chemical, vol. 145, no. 1, pp. 553-560, 2010.

[7] K. F. Lei and P. H. M. Leung, "Microelectrode array biosensor for the detection of Legionella pneumophila," Microelectronic Engineering, vol. 91, pp. 174-177, 2012.

[8] X. Li, F. Zhang, J. Shi et al., "Microfluidic devices with disposable enzyme electrode for electrochemical monitoring of glucose concentrations," Electrophoresis, vol. 32, no. 22, pp. 3201-3206, 2011.

[9] L. Zhang, P. Qu, J. Sheng, J. Lei, and H. Ju, "Open tubular microreactor with enzyme functionalized microfluidic channel for amperometric detection of glucose," Chinese Journal of Chemistry, vol. 30, no. 9, pp. 2145-2150, 2012.

[10] S. Borgmann, A. Schulte, S. Neugebauer, and W. Schuhmann, "Amperometric biosensors," in Advances in Electrochemical Science and Engineering, R. C. Alkire, D. M. Kolb, and J. Lipkowski, Eds., pp. 1-83, Wiley-VCH, 2011.

[11] J. Sheng, L. Zhang, J. Lei, and H. Ju, "Fabrication of tunable microreactor with enzyme modified magnetic nanoparticles for microfluidic electrochemical detection of glucose," Analytica Chimica Acta, vol. 709, pp. 41-46, 2012.

[12] S. F. D'Souza, "Immobilization and stabilization of biomaterials for biosensor applications," Applied Biochemistry and Biotechnology, vol. 96, no. 1-3, pp. 225-238, 2001.

[13] A. Sassolas, L. J. Blum, and B. D. Leca-Bouvier, "Immobilization strategies to develop enzymatic biosensors," Biotechnology Advances, vol. 30, no. 3, pp. 489-511, 2012.

[14] C. Karuwan, A. Wisitsoraat, T. Maturos et al., "Flow injection based microfluidic device with carbon nanotube electrode for rapid salbutamol detection," Talanta, vol. 79, no. 4, pp. 9951000, 2009.

[15] K.-W. Lin, Y.-K. Huang, H.-L. Su, and Y.-Z. Hsieh, "In-channel simplified decoupler with renewable electrochemical detection for microchip capillary electrophoresis," Analytica Chimica Acta, vol. 619, no. 1, pp. 115-121, 2008.

[16] A. J. Bard and L. R. Faulkner, "Techniques based on concepts of impedance," in Electrochemical Methods: Fundamentals and Applications, pp. 368-416, John Wiley \& Sons, New York, NY, USA, 2001.

[17] I. J. Gaitan, S. C. Medina, J. C. González et al., "Evaluation of toxicity and degradation of a chlorophenol mixture by the laccase produced by Trametes pubescens," Bioresource Technology, vol. 102, no. 3, pp. 3632-3635, 2011.

[18] J. H. Waterborg, "The Lowry method for protein quantitation," in The Protein Protocols Handbook, J. M. Walker, Ed., pp. 7-10, Humana Press, Totowa, NJ, USA, 2009.

[19] M. H. Ghanim and M. Z. Abdullah, "Integrating amperometric detection with electrophoresis microchip devices for biochemical assays: recent developments," Talanta, vol. 85, no. 1, pp. 28$34,2011$.
[20] L. F. Urrego, D. I. Lopez, K. A. Ramirez, C. Ramirez, and J. F. Osma, "Biomicrosystem design and fabrication for the human papilloma virus 16 detection," Sensors and Actuators B: Chemical, vol. 207, pp. 97-104, 2015.

[21] E. Sabatani and I. Rubinstein, "Organized self-assembling monolayers on electrodes. 2. Monolayer-based ultramicroelectrodes for the study of very rapid electrode kinetics," Journal of Physical Chemistry, vol. 91, no. 27, pp. 6663-6669, 1987.

[22] E. Sabatani, I. Rubinstein, R. Maoz, and J. Sagiv, "Organized self-assembling monolayers on electrodes: part I. Octadecyl derivatives on gold," Journal of Electroanalytical Chemistry, vol. 219, no. 1-2, pp. 365-371, 1987.

[23] C. Galhaup, S. Goller, C. K. Peterbauer, J. Strauss, and D. Haltrich, "Characterization of the major laccase isoenzyme from Trametes pubescens and regulation of its synthesis by metal ions," Microbiology, vol. 148, no. 7, pp. 2159-2169, 2002.

[24] B. Patil, S. Fujikawa, T. Okajima, and T. Ohsaka, "Enzymatic direct electron transfer at ascorbate oxidase-modified gold electrode prepared by one-step galvanostatic method," International Journal of Electrochemical Science, vol. 7, no. 6, pp. 5012-5019, 2012.

[25] N. Matsumoto, X. Chen, and G. S. Wilson, "Fundamental studies of glucose oxidase deposition on a Pt electrode," Analytical Chemistry, vol. 74, no. 2, pp. 362-367, 2002.

[26] J. C. Gonzalez, S. C. Medina, A. Rodriguez, J. F. Osma, C. J. Alméciga-Díaz, and O. F. Sánchez, "Production of Trametes pubescens laccase under submerged and semi-solid culture conditions on agro-industrial wastes," PLoS ONE, vol. 8, no. 9, Article ID e73721, 2013.

[27] S. Chawla, R. Rawal, S. Sharma, and C. S. Pundir, "An amperometric biosensor based on laccase immobilized onto nickel nanoparticles/carboxylated multiwalled carbon nanotubes/polyaniline modified gold electrode for determination of phenolic content in fruit juices," Biochemical Engineering Journal, vol. 68, pp. 76-84, 2012.

[28] M. E. Çorman, N. Öztürk, N. Bereli, S. Akgöl, and A. Denizli, "Preparation of nanoparticles which contains histidine for immobilization of Trametes versicolor laccase," Journal of Molecular Catalysis B: Enzymatic, vol. 63, no. 1-2, pp. 102-107, 2010.

[29] S. Chawla, R. Rawal, Shabnam, R. C. Kuhad, and C. S. Pundir, "An amperometric polyphenol biosensor based on laccase immobilized on epoxy resin membrane," Analytical Methods, vol. 3, no. 3, pp. 709-714, 2011.

[30] D.-S. Jiang, S.-Y. Long, J. Huang, H.-Y. Xiao, and J.-Y. Zhou, "Immobilization of Pycnoporus sanguineus laccase on magnetic chitosan microspheres," Biochemical Engineering Journal, vol. 25, no. 1, pp. 15-23, 2005.

[31] D. Quan, Y. Kim, and W. Shin, "Characterization of an amperometric laccase electrode covalently immobilized on platinum surface," Journal of Electroanalytical Chemistry, vol. 561, no. 1, pp. 181-189, 2004.

[32] Y. Liu, X. Qu, H. Guo, H. Chen, B. Liu, and S. Dong, "Facile preparation of amperometric laccase biosensor with multifunction based on the matrix of carbon nanotubes-chitosan composite," Biosensors and Bioelectronics, vol. 21, no. 12, pp. 2195-2201, 2006.

[33] D. Quan, Y. Kim, K. B. Yoon, and W. Shin, "Assembly of laccase over platinum oxide surface and application as an amperometric biosensor," Bulletin of the Korean Chemical Society, vol. 23, no. 3, pp. 385-390, 2002. 
[34] R. Fogel and J. L. Limson, "Electrochemically predicting phenolic substrates' suitability for detection by amperometric laccase biosensors," Electroanalysis, vol. 25, no. 5, pp. 1237-1246, 2013.

[35] R. Rawal, S. Chawla, and C. S. Pundir, "Polyphenol biosensor based on laccase immobilized onto silver nanoparticles/multiwalled carbon nanotube/polyaniline gold electrode," Analytical Biochemistry, vol. 419, no. 2, pp. 196-204, 2011.

[36] D. Brondani, C. W. Scheeren, J. Dupont, and I. C. Vieira, "Biosensor based on platinum nanoparticles dispersed in ionic liquid and laccase for determination of adrenaline," Sensors and Actuators B: Chemical, vol. 140, no. 1, pp. 252-259, 2009.

[37] Y. Zhang, G.-M. Zeng, L. Tang, D.-L. Huang, X.-Y. Jiang, and Y.N. Chen, "A hydroquinone biosensor using modified core-shell magnetic nanoparticles supported on carbon paste electrode," Biosensors \& Bioelectronics, vol. 22, no. 9-10, pp. 2121-2126, 2007.

[38] V. S. Bagotsky, "Nonaqueous electrolytes," in Fundamentals of Electrochemistry, pp. 128-137, Wiley-Interscience, Hoboken, NJ, USA, 2006. 

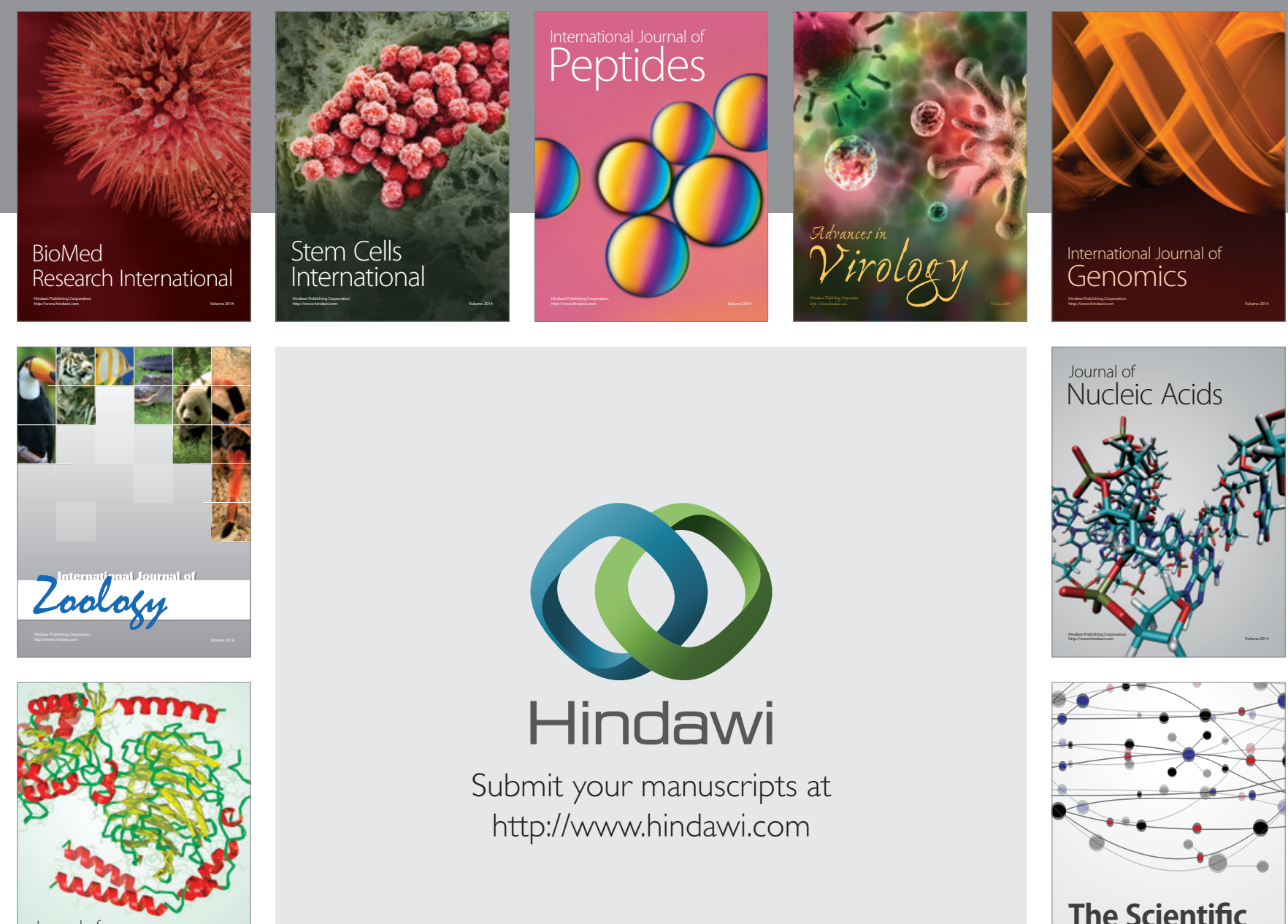

Submit your manuscripts at

http://www.hindawi.com

Journal of
Signal Transduction
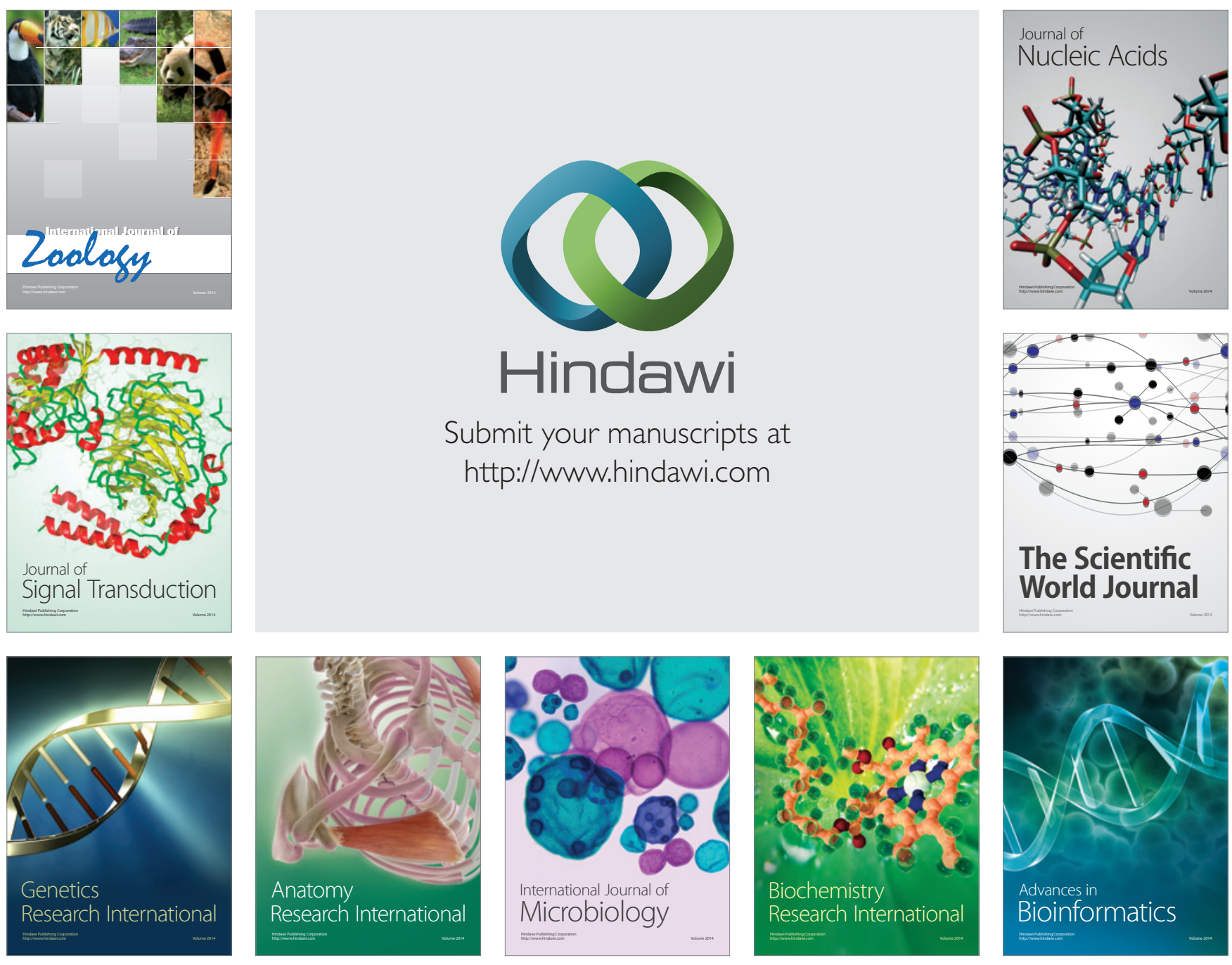

The Scientific World Journal
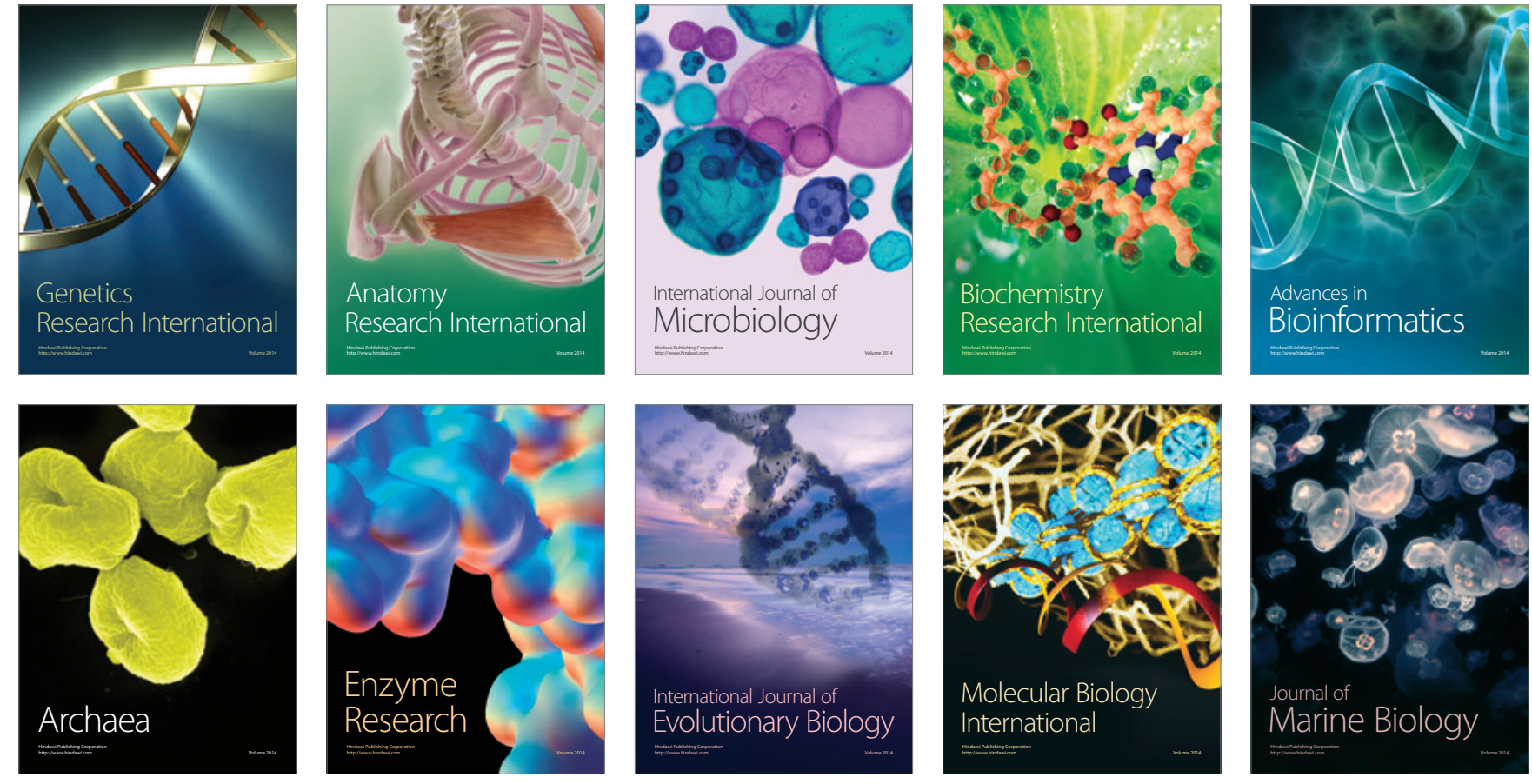